\title{
The role of infection control within the ultrasound unit
}

Ultrasound technology has rapidly evolved over the past decade with increased use to aid in the diagnosis of a variety of medical conditions. With the ease of smaller portable machines and frequent use, comes the risk of improper hygiene and lack of disinfection of equipment post patient use. The prevalence of healthcare associated infections ranges from 1.7 million in the US (Klevens et al., 2007) to 200000 in Australia (Cruickshank and Ferguson, 2008) and antimicrobial resistance is now considered a global threat. The infectious status of a patient is not often disclosed to the ultrasound user and this poses a risk for the transmission of infection from patient to ultrasound user or to the next patient if the ultrasound equipment has not been cleaned between use. Many ultrasound training programs focus on the technological aspects of scanning but do not cover training in basic infection, prevention and control.

There have been reported cases of infection resulting from ultrasound guided procedures (Cervini et al., 2010; Ferhi et al., 2013; Hiyama et al., 2016) and a fatality due to Hepatitis B infection after failure to decontaminate a transoesophageal transducer (Medical safety alert: No. MDA/2012/ 038). Keys et al (2015) highlighted that over $60 \%$ of ultrasound transducers were covered in blood and bodily fluids in the Emergency department. This statistic is not surprising given the 'unclean' ultrasound transducers that are found within departments with visible dried blood ( $\triangleright$ Fig. 1 ). Other studies have shown that the entire ultrasound unit can be contaminated by various microorganisms, both commensals and potential patho- gens (Alfa et al., 2015; Westerway et al., 2016). Apart from ultrasound equipment, the gel poses a potential risk of transmission of infection. Ultrasound gel is conducive to microbial growth, especially when reheated and the lid left open allowing entry of microorganisms. Infections associated with contaminated ultrasound gel have been reported (Cheng et al 2016; Chittick et al., 2013; Oleszkowicz et al., 2012, Abdelfattah et al., 2017) including an outbreak of Burkholderia cenocepacia infection following ultrasound guided central line placement attributed to sterile gel (Shaban et al., 2017). Furthermore, 2 patients died as a result of septic shock from contaminated ultrasound gel used in central line placement (Abdelfattah et al., 2017). This highlights the importance of government regulation, strict testing and efficient labelling of products. As such, the 


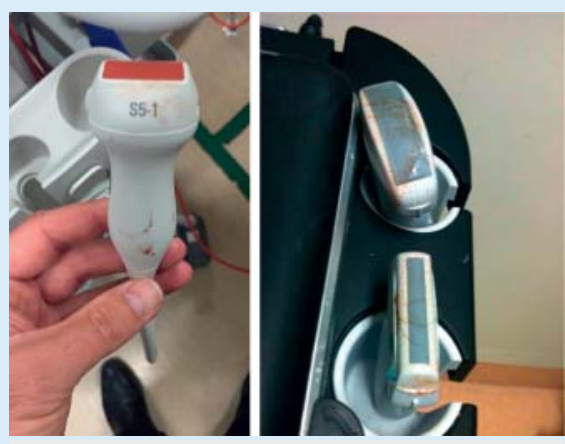

- Fig. 1 Blood contaminated ultrasound transducers.

entire ultrasound unit including gel should be considered as a potential vector in the transmission of a healthcare associated infection.

In an attempt to further comprehend the hygiene and disinfection practices within the ultrasound unit, a survey was launched by the World Federation for Ultrasound in Medicine and Biology (WFUMB) via its six Federations (Basseal and Westerway, 2017). Results from the United Kingdom indicated that ultrasound users were overwhelmed with high throughput of patients which potentially affected the ability to clean the ultrasound equipment (Westerway and Basseal, 2017a). Similar results were obtained from the Australasian region, which illustrated that non-approved agents were utilised for high level disinfection of ultrasound transducers and approximately half of the respondents do not receive any support from their infection control department (Westerway and Basseal, 2017b).

These findings indicated a gap in knowledge of basic infection prevention and control education as well as a lack of support in the area.

Many ultrasound organisations as well as national health agencies are responsible for producing best practice guidelines for optimal patient care. The Australasian Society for Ultrasound in Medicine (ASUM - the peak body for ultrasound in Australasia) in collaboration with the Australasian College of Infection Prevention and Control (ACIPC - the peak body for infection prevention and control in Australasia) released joint "Guidelines for Reprocessing Ultrasound
Transducers" (Basseal et al., 2017). These comprehensive guidelines include flowcharts for best reprocessing practice and will form the framework for the WFUMB guidelines to be published shortly. It would be sensible for all users of ultrasound to undertake basic infection control training and study the published Guidelines to ensure optimal patient safety during an ultrasound examination.

Susan Campbell Westerway

World Federation of Ultrasound in Medicine \& Biology

Australasian Society for Ultrasound in

Medicine, NSW Australia

scwus@hotmail.com

Jocelyne M Basseal

Australasian Society for Ultrasound in

Medicine, NSW Australia

j.basseal@asum.com.au

\section{References}

1. Klevens, R Monina et al. "Estimating Health Care-associated Infections and Deaths in U.S. Hospitals, 2002." Public Health Reports 122.2 (2007): 160 - 166.

2. Cruickshank M and Ferguson J (eds) (2008) Reducing Harm to patients from Health care Associated Infection: The Role of Surveillance. Australian Commission for Safety and Quality in Health Care. p3.

3. Cervini P, Hesley GK, Thompson RL, Sampathkumar P, Knudsen JM. Incidence of infectious complications after an ultrasound-guided intervention. Am J Roentgenol 2010; 195: 846 - 50.

4. Ferhi K, Rouprêt TM, Mozer P, Ploussard G, Haertig A, De La Taille A. Hepatitis C transmission after prostate biopsy. Case Rep Urol, 2013; 2013: e797 248.

5. Hiyama Y, Takahashi S, Uehara T, Ichihara K, Hashimoto J, Masumori N. A case of infective endocarditis and pyogenic spondylitis after transrectal ultrasound guided prostate biopsy. J Infect Chemother 2016; 22: $767-9$.

6. Medicines and Healthcare products Regulatory Agency. Reusable transoesophageal echocardiography, transvaginal and transrectal ultrasound probes (transducers) - failure to appropriately decontaminate Medical safety alert - GOV.UK (No. MDA/2012/038); 2012. Available from: https://www.gov.uk/ drug-device-alerts/medical-device-alertreusable-transoesophageal-echocardiography-transvaginal-and-transrectal-ultrasound-probes-transducers-failure-to-appropriately-decontaminate.

7. Keys, M., Sim, B., Thom, O., Tunbridge, M., Barnett, A., \& Fraser, J (2015). Efforts to Attenuate the Spread of Infection (EASI): a prospective, observational multicenter survey of ultrasound equipment in Australian emergency departments and intensive care units. Critical Care and Resuscitation Vol 17 (1):43-6

8. Westerway S, Basseal JM, Brockway A, Hyett JA, Carter DA. Potential risks associated with an ultrasound examination - a bacterial perspective. J Ultrasound Med Biol 2016; 43: $421-6$.

9. Alfa MJ. Intra-cavity ultrasound probes: cleaning and high-level disinfection are necessary for both the probe head and handle to reduce the risk of infection transmission. Infect Control Hosp Epidemiol 2015; 36: $585-6$.

10. Cheng $A$, Sheng $W-H$, Huang $Y-C$, Sun $\mathrm{H}-\mathrm{Y}$, Tsai $\mathrm{Y}-\mathrm{T}$, Chen M-L, et al. Prolonged postprocedural outbreak of Mycobacterium massiliense infections associated with ultrasound transmission gel. Clin Microbiol Infect 2016; 22: 382.e1 - 11.

11. Chittick P, Russo V, Sims M, RobinsonDunn B, Oleszkowicz S, Sawarynski K, et al. An outbreak of Pseudomonas aeruginosa respiratory tract infections associated with intrinsically contaminated ultrasound transmission gel. Infect Control Hosp Epidemiol 2013; 34: $850-3$

12. Oleszkowicz $S$, Chittick P, Russo $V$ et al. Infections associated with the use of ultrasound transmission gel: proposed guidelines to minimize risk. Infect Control Hosp Epidemiol 2012; 33:1235-1237.

13. Abdelfattah R, Aljumaah S, Alqahtani A, Althawadi S, Barron I, Almofada S. Outbreak of Burkholderia cepacia bacteraemia in a tertiary care centre due to contaminated ultrasound probe gel. Journal of Hospital Infection. 2017; pii: S0195 - 6701(17)30516- 9 14. Shaban RZ, Maloney S, Gerrard J, Collignon $\mathrm{P}$, et al. Outbreak of health careassociated Burkholderia cenocepacia bacteremia and infection attributed to contaminated sterile gel used for central line insertion under ultrasound guidance and other procedures. American Journal of Infection Control. 2017; 45(9):954- 958 
15. Basseal JM and Westerway SC. Disinfection and Hygiene Practice in Medical Ultrasound: WFUMB Survey Results. Presented at the 16th World Federation for Ultrasound in Medicine and Biology (WFUMB) Congress. Taipei, Taiwan 13-17 October 2017.

16. Westerway SC and Basseal JM (2017a). The ultrasound unit and infection control -
Are we on the right track? Ultrasound. Volume: 25 issue: 1 , page(s): $53-57$.

17. Westerway SC and Basseal JM (2017b). Advancing infection control in Australasian medical ultrasound practice. Australasian Journal of Ultrasound in Medicine. Volume 20, Issue 1:Pages 26-29

18. Basseal JM, Westerway SC, Juraja M, F van de Mortel T, McAuley TE, Rippey J, et al. Guidelines for Reprocessing Ultrasound
Transducers. Australas J Ultrasound Med 2017; 20: 30 - 40. Accessed via: http://onlinelibrary.wiley.com/doi/10.1002/ ajum.12042/abstract

For information from the EFSUMB Committee on Medical Ultrasound Safety (ECMUS) visit the EFSUMB webite

http://www.efsumb.org/safety/resources/ 2017-probe_cleaning.pdf 